\title{
On an application of multi-material composite laminates in the aerospace sector
}

\author{
Hans Luinge ${ }^{1} \cdot$ Laurent L. Warnet ${ }^{2}$ (D) \\ Received: 19 January 2020 / Revised: 29 May 2020 / Accepted: 20 June 2020 / Published online: 9 July 2020 \\ (C) The Author(s) 2020
}

\begin{abstract}
This paper explores the possibility to use shredded thermoplastic laminates as one of the plies within a laminate. The focus lies in potential performance decrease due to the presence of such compounds within the laminate. For this purpose, a typical application of a stampformed thermoplastic-based laminate is taken as a basis. In this application, the replacement of mid-plane layers by a moulding compound is considered. The performance knockdown is evaluated using a series of tests typically related to the application. The results of bending, bearing and curved beam tests are reported and analysed. The results show that the replacement of continuous fibres by shredded laminates does not affect significantly the performance of the material for the chosen properties. The applicability of such hybrid laminates is further discussed based on these results.
\end{abstract}

Keywords Thermoplastic composites $\cdot$ Hybrid laminates $\cdot$ Recycling

\section{Introduction}

Thermoplastic-based composite materials meant for (semi) structural applications can be categorised according to their fibre length, fibre content and processability. Continuous fibre-reinforced systems are often pressed or stampformed into shell-like products having a relatively low degree of complexity, which are subsequently assembled into more complex structures [1]. Discontinuous long fibre-reinforced systems can be processed with compression moulding, leading to products potentially having a higher degree of complexity though showing generally lower mechanical performance than the continuous fibre-reinforced materials.

An interesting recent application of compression moulding is the reprocessing of recycled shredded thermoplastic composites, as illustrated for example by Abdul Rasheed [2] and Vincent [3], where ground (production) laminate scrap is

Laurent L. Warnet

l.warnet@utwente.nl

Hans Luinge

h.luinge@toraytac-europe.com

1 Toray Advanced Composites, G. van der Muelenweg 2, Nijverdal, the Netherlands

2 University of Twente, Drienerlolaan 5, Enschede, the Netherlands used. Here again, the mechanical properties of such products remain way lower to those of their original counterparts.

The study presented in this paper proposes to evaluate the use of thermoplastic composite production cut-outs in the form of shredded moulding compound in combination with continuous fibre-reinforced thermoplastic laminates. The main goal is to demonstrate the potential of using thermoplastic composite scrap in a (semi) structural application, by choosing the recycled material as one of the plies within a traditional laminate. The key element in order to prevent the performance knock-down of the moulding compound will be to prevent having the recycled material along the main loading path. When successful, the use of recycled materials in traditional laminates would potentially reduce the cost of laminates, as well as enlarge the design parameters available for the designer when developing a laminate.

The paper first presents some possible criteria used to support the design of a laminate made of a weighted amount of continuous fibre-reinforced thermoplastic and recycled moulding compound. This is argued based on a generic thermoplastic composite product which is used in the aerospace sector to connect fuselage skin to stiffeners. Typical load cases are considered in order to propose a laminate lay-up where a basic material in combination with a few alternative 'filler' materials will be proposed. Besides recycled shredded laminates, a standard moulding compound and typical hybrid alternatives will be proposed. The chosen load cases will lead to 
the selection of a few testing methods, needed to evaluate the performance of the new laminates. Results of these tests are evaluated and discussed.

\section{Basic hybrid laminate}

\subsection{Generic product}

A typical aerospace product is chosen as a basis for this study. Brackets are products used for the assembly of the fuselage to longitudinal stiffeners, frames and floor beams. A few examples are shown in Fig. 1 a, showing mostly flat surfaces with curved corners, often featuring holes at places where the load is transferred to a next part. Though these products seem relatively simple, typical specifications to be fulfilled are broad as they do not only concern mechanical performance but also for example tolerance on process-related deformation and their ability to be assembled to other products. More than 4000 of such products in various shapes are for example used in the assembly of an Airbus A350. The process of choice for these brackets is thermoforming, meaning the material used is a thermoplastic-based composite laminate. Current applications of these brackets use woven carbon-reinforced polyphenylene sulfide (PPS) or polyether ether ketone (PEEK). As illustrated in Fig. 2, the thermoforming (or stampforming) is based on a thermoplastic composite laminate which, after being cut to size as a blank, is subsequently infrared-heated, before being pressed and cooled down between matched metal tools or a combination of metal and rubber tooling.

\subsection{Typical loading considered}

When considering a simplified bracket as illustrated in Fig. 1 $\mathrm{b}$, a designer would orient the fibres in the length direction to optimise bending properties in the curved corner. As soon as a bracket features a number of corners, a cross-ply lay-up becomes inevitable. Besides, bearing properties for the load transfer will be optimised with a quasi-isotropic lay-up in the neighbourhood of the hole. The practical solution is to have a quasi-isotropic lay-up throughout the bracket, as it would be production-wise an issue to vary the lay-up/the thickness along the area of the bracket. Some optimisation can be made in the position of the layers through the thickness. Still, the same type of material is usually chosen throughout the laminate. This opens the question whether it would be possible to replace certain layers being less loaded by a less performant — and hopefully cheaper material, for example a moulding compound based on laminate cutting rests.

In terms of loading, a few generic loading scenarios can be put forward. The assembly of a bracket with a frame means some bending moments will be applied on the flat part of a bracket as illustrated in Fig. 1 b. Also the curved part will be subjected to a bending type of loading. The transfer of load through the bracket means that bearing situation will need to be considered. This paper will focus on the first instance on these load cases. A simple analysis of the occurring deformations and stresses will help decide on the layers which can potentially be replaced by alternative materials. It is known from simple Euler beam analysis that under a bending moment, maximal tensile and compression deformation occur at the outer layers of the laminate, while maximal out-of-plane shear stresses can be found in the mid layers. This observation, valid for the case bending, is dominant and leads to the search for an alternative material for the mid-plane layers while retaining the basic material for the outer layers. In more detail, criteria for selecting such materials are as follows:

- The mid-plane layer should be able to transfer shear through the thickness, meaning the shear modulus $G_{\mathrm{xz}}$ and the through thickness shear strength $S_{\mathrm{xz}}$ are equivalent to the current material.

- The mid-plane layers should be able to sustain the consolidation pressure and temperature during pressing of the laminate, as well as during the stampforming process.

- Besides, the mid-plane layers should have a minimum negative effect on the bearing strength $S_{\mathrm{b}}$ of the laminate.

- The out-of-plane tensile strength $S_{z}$, which is the main property governing the strength of the corner loaded under bending, should be similar to that of the base laminate.
Fig. 1 a Typical stampformed brackets used in the aerospace industry. b A simplified model of a bracket, having a single curvature curved part and a hole for assembly a

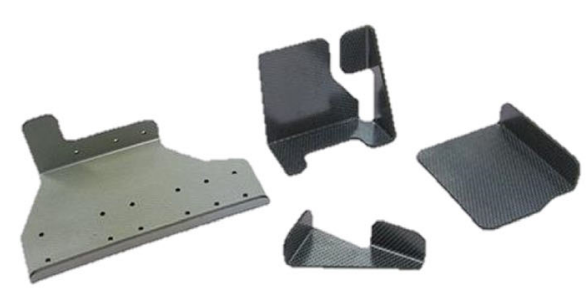

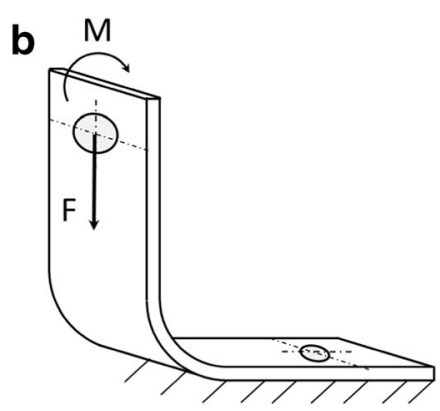


Fig. 2 Main steps in the stampforming process

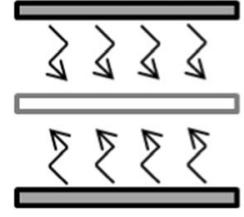

Laminate
IR heating

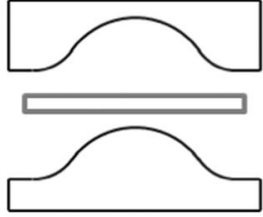

Pressing

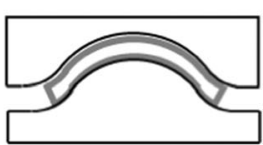

Cooling

\subsection{Materials selected}

According to the criteria proposed in the last paragraph, a selection of materials is put forward, chosen to be compatible with a Toray CETEX TC1100 5H Satin T300reinforced PPS. The nominal thickness of this woven fabric layer is $0.3 \mathrm{~mm}$, and the fibre volume fraction $v_{f}$ is 0.5 . The basic lay-up is a quasi-isotropic $[(0,90) /(+/-45) /$ $(-/+45) /($ MidLayer $)]_{\mathrm{s}}$, where the $2 \mathrm{mid}$ layers are left open for use of the alternative material. The materials retained in this study are also based on a PPS matrix in order to maximise the compatibility with the basis material as well as unifying the process conditions. Two types of carbon-based moulding compound are chosen from a preliminary study [4], i.e. $10 \mathrm{~mm} \times 20 \mathrm{~mm}$ cut unidirectional (UD) tapes at a $v_{f}$ of $60 \%$, and laminate chips which are ground from production laminate nesting rests. The typical size of the fibres resulting from the laminate grinding operation lies between 2 and $10 \mathrm{~mm}$. Density measurements confirmed a $50 \%$ fibre volume fraction of the ground laminate. A layer pressed from both these forms of moulding compounds illustrates the structure of both types of moulding compound. The result is shown in Fig. 3 a for the UD-based moulding compound (coded $\mathrm{MC1} 100$ ) and in Fig. $3 \mathrm{~b}$ for the ground compound (coded GC1100). Two types of glass-woven fabric are also considered as an alternative meant at reducing the cost of the laminate as well as a classical multi-material hybrid laminate [5]. A reference laminate with $2(0,90)$ layers of the original material as mid layers is also represented in the experimental program. The materials considered are summarised in Table 1 . It is worth adding that the variety in mid-plane materials led to a range of laminate thicknesses as reproduced in the last column of Table 1.

\section{Test program}

\subsection{Test specimen preparation}

The laminates considered in this study were all pressconsolidated between two caul sheets coated with a Marbo release agent. The standard press cycle used is illustrated in Fig. 4. It is worth adding at this point that both flexural and bearing specimens are based on flat press-consolidated laminates, while the curved beam specimens were stampformed. This difference in processing technique is known to lead to a variation in properties, in particular those dominated by the matrix [6]. The influence of the hybrid layer on the total thickness of the blank (see Table 1) meant a rubber mould-based stampforming process was preferred in order to guarantee a homogeneous consolidation pressure over the full specimen, although leading to a difference in thickness between the flat and curved parts. A negative rubber mould was used. The cycle used is depicted in Fig. 5.

\subsection{Testing methods}

A series of test methods is selected in order to support the criteria given in the last sections and provide a quantitative evaluation of the influence of the type of mid-plane layers on the properties of the material/product. The tests performed are
Fig. 3 a Single layer of pressed $10 \mathrm{~mm} \times 20 \mathrm{~mm}$ UD C-PPS tape. b Single layer of pressed ground laminate waste
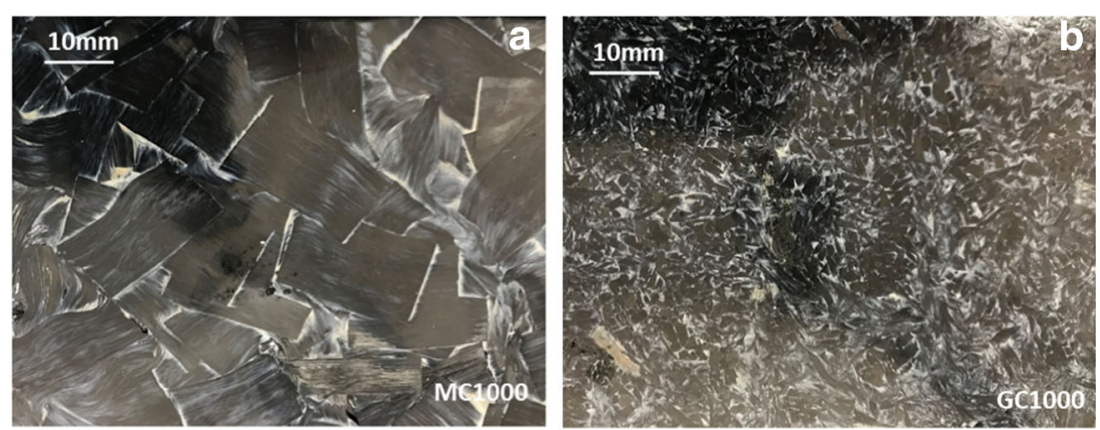
Table 1 Materials considered as an alternative for the mid layers

\begin{tabular}{lll}
\hline $\begin{array}{l}\text { Material } \\
\text { code }\end{array}$ & MidLayer in $[(0,90) /(+/-45) /(-/+45) /(\text { MidLayer })]_{\mathrm{s}}$ & $\begin{array}{l}\text { Laminate thickness } \\
(\mathrm{mm})\end{array}$ \\
\hline Reference & 1 layer CETEX TC1100 5H Satin T300-reinforced PPS & 2.5 \\
Glass A & 1 layer CETEX TC1100 8H Satin E glass-reinforced PPS & 2.3 \\
Glass B & $1 / 2$ layer Owens Corning 2xTwill WRT0600 g/m ${ }^{2}$-PPS film & 2.2 \\
MC1100 & $\begin{array}{c}10 \text { mm } \times 20 \text { mm UD CETEX MC1100 C-PPS moulding com- } \\
\text { pound }\end{array}$ & 2.7 \\
GC1100 & \begin{tabular}{l} 
Ground production laminate with fibre length 2-10 mm \\
\hline
\end{tabular} \\
\hline
\end{tabular}

a flexural test, a bearing strength test and a curved beam tests and are described shortly in the following parts.

\subsubsection{Flexural test method}

A simply supported three-point bending flexural test method (EN 2562 [7]) is used to evaluate the bending flexural stiffness, the bending stress at fracture and the fracture mode. Output of this test is the bending modulus $E_{b}$ and the maximum stress $\sigma_{b}$. The bending modulus is calculated based on the Euler-Bernoulli beam theory

$E_{b}=\frac{l_{s}^{3}}{48 b h^{3} c_{b}}$

with $c_{b}$ the bending compliance as measured in the first linear part of the force-deflection graph. The maximum stress is based on the same type of analysis method and reads.

$\sigma_{b}=\frac{3 F_{\max } l_{s}}{2 b h^{2}}$

where it is assumed that the fracture occurs at the maximum force and at $x=l_{s} / 2$.

Table 2 summarises the main testing parameters used.

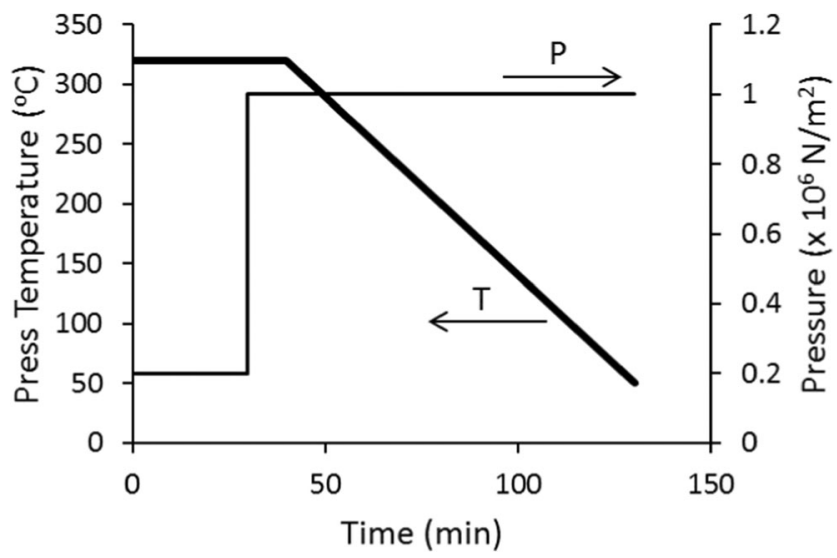

Fig. 4 Press consolidation cycle of T300-PPS laminates

\subsubsection{Bearing test}

A bolt bearing test (AITM 1-0009 [8]) is used to evaluate the behaviour of the hybrid laminate under bolt bearing conditions. The specimen is a rectangular specimen featured with a 6.3-mm-diameter hole close to an edge of the specimen. The specimen is clamped on one side by traditional jaws, whereas the load is transferred at the other side by a bolt connecting the specimen and two metal plates, tightened with a $1.3-\mathrm{Nm}$ torque. The hole deformation is evaluated using a clip-on extensiometer. Table 3 lists the main testing parameters used. Output of this test is the initial peak bearing stress $\sigma_{i}$ and the ultimate bearing stress $\sigma_{u}$. The bearing stresses are respectively evaluated from the load $F_{i}$ defined by the initial peak/inflection point on the bolt bearing test curve and the maximum force $F_{u}$

$\sigma_{i}=\frac{F_{i}}{2 r h} ; \sigma_{u}=\frac{F_{u}}{2 r h}$

\subsubsection{Curved beam strength test}

A curved beam strength test (AITM 1-0069 [9]) designed as a simply supported four-point bending set-up and a folded beam

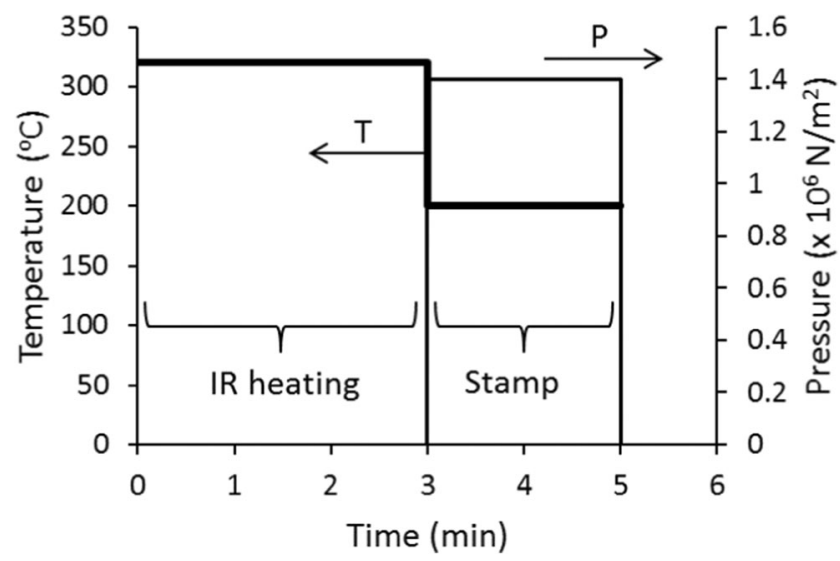

Fig. 5 Stampforming cycle of T300-PPS curved beam specimens, with a heating phase and a stamping phase. The temperature in the stamping phase concerns that of the positive metal part. The negative rubber mould is kept at room temperature 
Table 2 Main flexural test method parameters

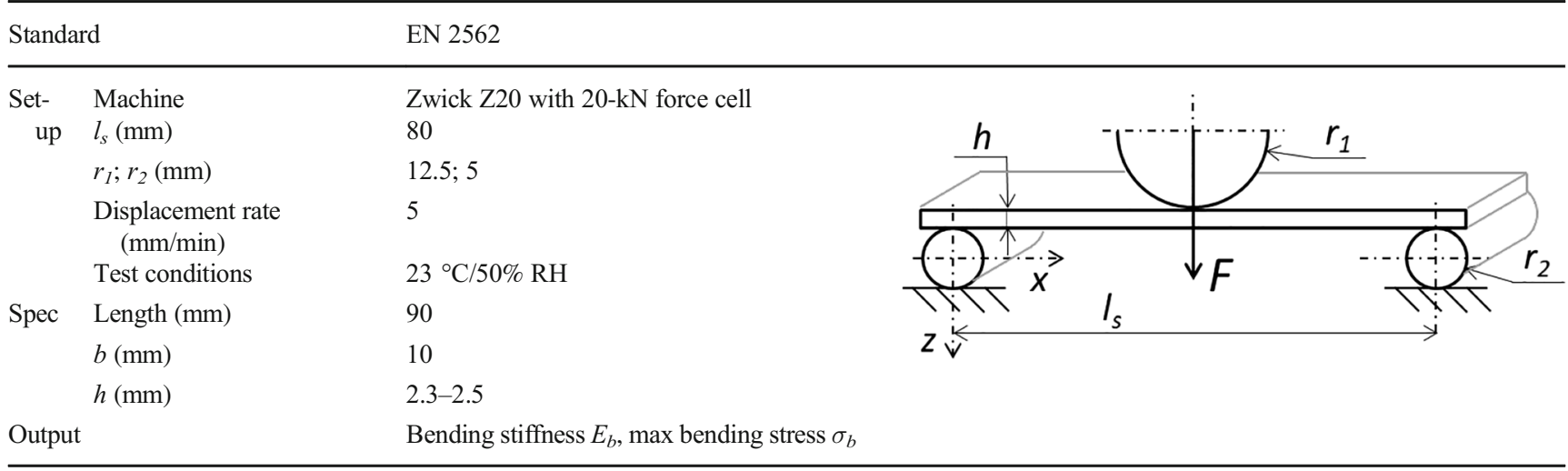

is meant to evaluate the through thickness behaviour of the laminate. Besides, the post stampforming spring forward deformation of the specimens is also analysed. Table 4 summarises the most important parameters involved in this test. The data is analysed using one of the methods proposed by the ASTM D6415:06 [10], evaluating the interlaminar tensile strength $\sigma_{z \text {, max }}$. The simplified approach proposed by Kedward [11] is used here:

$$
\begin{aligned}
\sigma_{z, \max } & =\frac{3 F l_{0}}{4 h b \sqrt{r_{i} r_{o}}} ; l_{0} \\
& =\frac{1}{2 \cos (\phi)}\left(\frac{l_{b}-l_{t}}{2 \cos (\phi)}+(2 r+h) \tan (\phi)\right)
\end{aligned}
$$

with the involved parameters as described in Table 4.

\section{Results}

\subsection{Flexural tests}

Typical force-displacement curves of the bending tests for the five types of mid-plane materials considered (Table 1) are shown in Fig. 6.
All specimens showed after fracture both signs of compressive and tensile failure modes as shown in a typical micrography taken under the loading cylinder in Fig. 6 b. No damage was observed in the mid-plane. A minimum of 5 specimens per sample was evaluated. The data analysis for the bending stiffness $E_{b}$ and stress at fracture $\sigma_{b}$ as defined in relations (1) and (2) and summarised in Table 5 as average with relative standard deviation ( $\mathrm{rsd}$ ) show that the differences in both stiffness and strength are contained. These results are shown graphically in Fig. 7, where the error bars indicate \pm one standard deviation.

\subsection{Bolt bearing tests}

Typical force-hole deformation curves of the bolt bearing tests for the materials considered (Table 1) are shown in Fig. 8.

All specimens failed according to a bearing fracture. A typical micrography of an ultimate bearing failure is shown in Fig. 8 b. Both initial and ultimate bearing stresses are extracted from these curves using relation (3). The average values and relative standard deviation based on a minimum of 5 specimens are reproduced in Table 6 . These results are shown graphically in Fig. 9, where the error bars indicate \pm one standard deviation. These results show no significant

Table 3 Main bearing test method parameters

\begin{tabular}{lll}
\hline Standard & & AITM 1-0009 \\
\hline Set-up & Machine & Zwick 1474 with 100-kN force cell \\
& $r(\mathrm{~mm})$ & 3.175 \\
& Displacement rate $(\mathrm{mm} / \mathrm{min})$ & 1 \\
Spec & Test conditions & $23{ }^{\circ} \mathrm{C} / 50 \% \mathrm{RH}$ \\
& Length $(\mathrm{mm})$ & 150 \\
Output & $b(\mathrm{~mm})$ & 45 \\
& $h(\mathrm{~mm})$ & $2.3-2.5$ \\
& & Initial peak bearing strength $\sigma_{i}$, \\
\hline
\end{tabular}


Table 4 Main curved beam test parameters

\begin{tabular}{|c|c|c|}
\hline \multicolumn{2}{|c|}{ Standard } & AITM 1-0069 for set-up and test procedure, ASTM D6415:06 for analysis \\
\hline $\begin{array}{l}\text { Set- } \\
\text { up }\end{array}$ & $\begin{array}{l}\text { Machine } \\
r(\mathrm{~mm})\end{array}$ & $\begin{array}{l}\text { Instron } 5982 \text { with } 10-\mathrm{kN} \text { force cell } \\
4\end{array}$ \\
\hline & $l_{b}, l_{t}, l_{o}$ & $41.9,21.7, f(\phi)$ \\
\hline & $\begin{array}{l}\text { Displacement rate } \\
\quad(\mathrm{mm} / \mathrm{min})\end{array}$ & 2 \\
\hline & Test conditions & $23{ }^{\circ} \mathrm{C} / 50 \% \mathrm{RH}$ \\
\hline \multirow[t]{4}{*}{ Spec } & $l(\mathrm{~mm})$ & 65 \\
\hline & $b(\mathrm{~mm})$ & 15 \\
\hline & $h(\mathrm{~mm})$ & $2.3-2.5$ \\
\hline & $r_{\mathrm{i}}, r_{\mathrm{o}}(\mathrm{mm})$ & $6.4,8.5-8.7$ \\
\hline \multicolumn{2}{|c|}{ Output } & $\begin{array}{l}\text { Spring forward } \Phi_{0} \text {, interlaminar tensile strength } \\
\quad \sigma_{z T}\end{array}$ \\
\hline
\end{tabular}

differences in both strength values and behaviour between the different types of hybrid laminates except for the glass B variant showing slightly lower values in particular for the ultimate value.

\subsection{Curved beam strength tests}

It is worth reminding that the curved beam produced by a negative rubber stampforming process led to a difference in thickness between the corner and the legs. A difference of up to $0.3 \mathrm{~mm}$ is observed. The interlaminar tensile strength results are based on the thickness measured in the corner of the specimens. Typical force-displacement curves of the curved beam strength tests for the materials considered (Table 1) are shown in Fig. 10.

All specimens showed a typical non-linear force-displacement behaviour followed by a brittle fracture, mostly leading to delaminations in the corner of the specimen as shown in Fig. 10 b. Most delaminations run according to undefined patterns, at least not clearly at the interface between the two types of materials. An exception concerns the specimens with the 'glass B' mid-plane material which shows a distinct behaviour with a lower stiffness and some sign of failure before the final fracture. No clear reason was observed for this behaviour. The interlaminar tensile strength (ILTS) is derived from the max force using relation (4). The average values and their relative standard deviation based on samples of 5 specimens are reproduced in Table 7 . Table 7 also reproduces the process-induced deformation results, showing a spring forward around $3^{\circ}$ with no clear difference amongst the hybrid laminates. The ILTS results are shown graphically in Fig. 11, where the error bars indicate \pm one standard deviation. The reference laminates show significantly higher interlaminar tensile strength values. Both moulding compound type fractures are at values lower by $10 \%$ (ground compound) to $20 \%$ (UD moulding compound). The glass reinforcement shows lower values for unknown reasons at this stage.

\section{Discussion}

The described results illustrate the possibility to develop stampformed parts using a certain percentage of shredded laminates as part of the basic blank. A generic product involving a number of loading case was considered and supports the design of a laminate suffering a minimum performance knock-down compared with a traditional single-material laminate. The results of the presented program show that the bending properties of the tailored laminate where the compound is used in the mid-plane are able to transfer through thickness shear. Besides, the moulding compound layer does not affect the failure behaviour in bearing condition and shows a limited knock-down factor in performance. The curved beam strength results confirm the good consolidation of the
Fig. 6 a Typical forcedisplacement curves of the bending tests. b Micrography of a typical bending fracture, showing both tensile and compressive induced crack formation
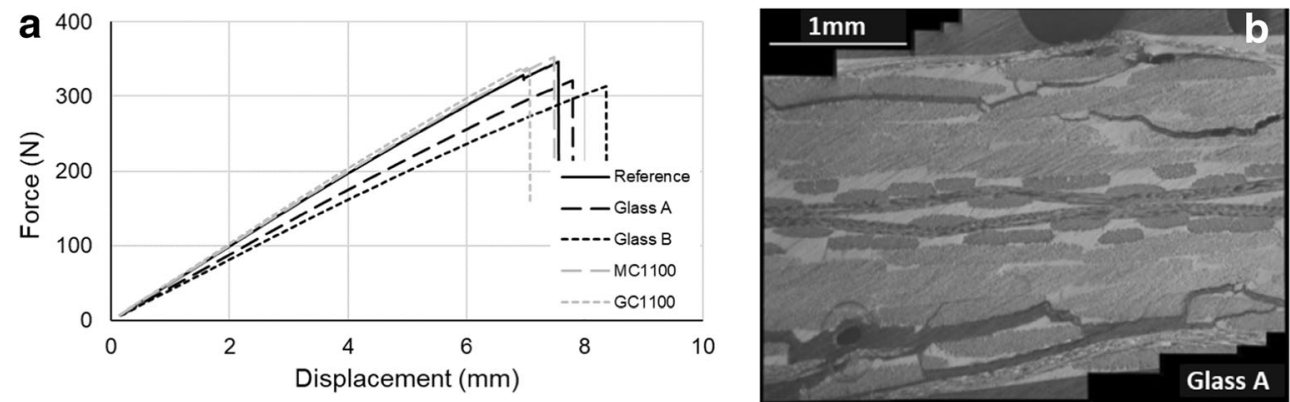
Table 5 Flexural test results

\begin{tabular}{llllll}
\hline Mid-plane material & Reference & Glass A & Glass B & MC1100 & GC1100 \\
\hline Sample size & 6 & 6 & 6 & 6 & 6 \\
$h(\mathrm{~mm})$ & 2.40 & 2.31 & 2.25 & 2.43 & 2.45 \\
$E_{b}\left(\times 10^{9} \mathrm{~N} / \mathrm{m}^{2}\right)$ & 46.0 & 45.9 & 45.6 & 42.7 & 44.2 \\
$\operatorname{rsd}(\%)$ & 0.4 & 1.3 & 1.5 & 2.6 & 3.0 \\
$\sigma_{b}\left(\times 10^{6} \mathrm{~N} / \mathrm{m}^{2}\right)$ & 728.6 & 725.0 & 716.4 & 688.9 & 684.0 \\
$\operatorname{rsd}(\%)$ & 5.0 & 7.8 & 4.8 & 4.2 & 3.7 \\
Fracture & Tens/Comp & Tens/Comp & Tens/Comp & Tens/Comp & Tens/Comp \\
\hline
\end{tabular}

Fig. 7 Flexural test results

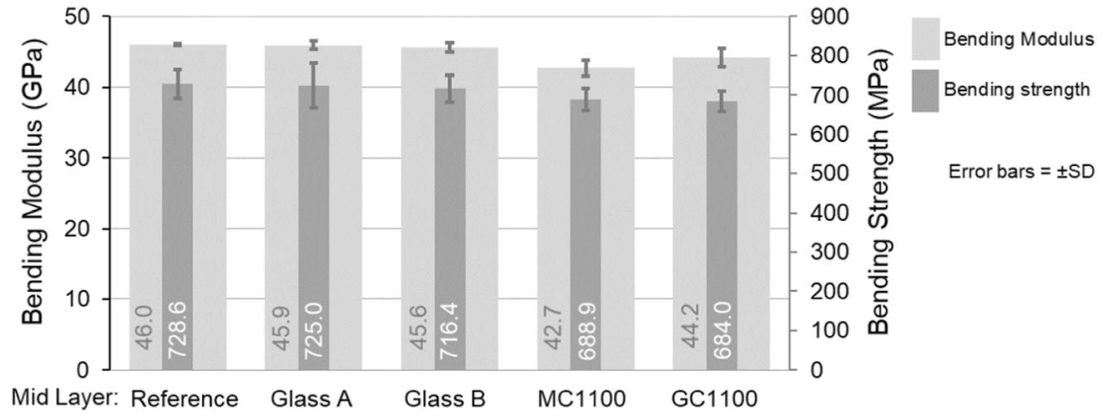

Fig. 8 a Typical force-dL curves of the bearing tests. $\mathbf{b}$ Picture of the surface of a GC1100 specimen at the ultimate bearing load
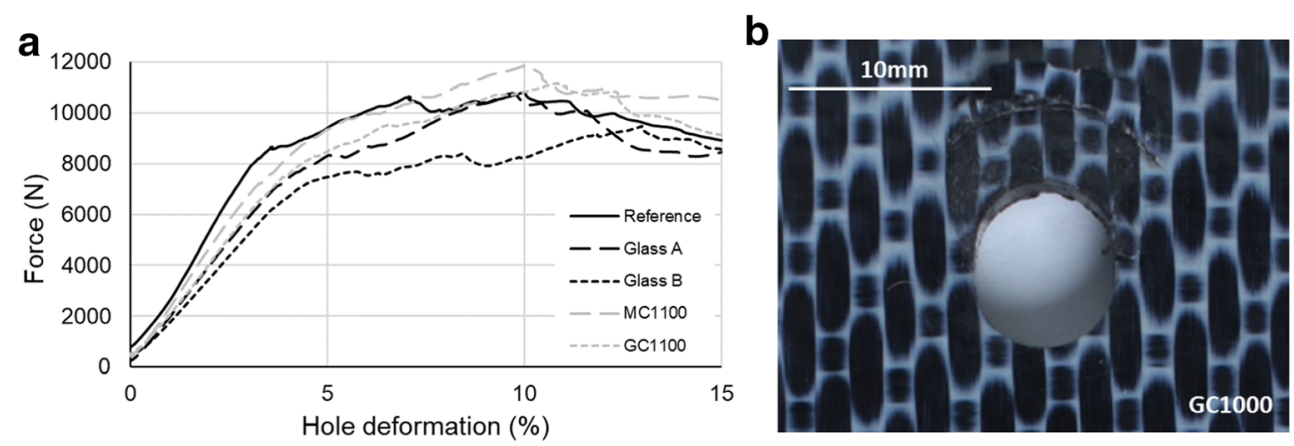

laminate through similar out-of-plane strength value as the traditional laminate. This last test also represents quantitative results related to the influence of the stampforming process, in

Table 6 Bolt bearing test results

\begin{tabular}{llllll} 
Mid-plane material & Reference & Glass A & Glass B & MC1100 & GC1100 \\
\hline Sample size & 5 & 5 & 5 & 6 & 5 \\
$h(\mathrm{~mm})$ & 2.43 & 2.33 & 2.3 & 2.48 & 2.47 \\
$\sigma_{i}\left(\times 10^{6} \mathrm{~N} / \mathrm{m}^{2}\right)$ & 559.9 & 529.9 & 508.7 & 544.1 & 528.9 \\
$\operatorname{rsd}(\%)$ & 6.8 & 5.3 & 2.9 & 9.6 & 12.5 \\
$\sigma_{u}\left(\times 10^{6} \mathrm{~N} / \mathrm{m}^{2}\right)$ & 717.7 & 693.6 & 652.9 & 741.3 & 722.9 \\
$\operatorname{rsd}(\%)$ & 4.9 & 3.2 & 2.3 & 6.6 & 4.4 \\
Fracture & Bearing & Bearing & Bearing & Bearing & Bearing \\
\hline
\end{tabular}

contrast to the other tests focussing on the blank and therefore material behaviour.

These results are illustrative and by no means meant to be optimised or serve as a basis for design rules. The use of such compounds will certainly affect other performance. Although not tested within this program, the tensile performances are for example expected to be lower, based on typical stiffness and strength values found in the recent literature [2].

Besides, a number of questions remain open in order to actually apply such materials within a laminate. These questions concern both the processing of the recycled material itself as its performance. Without starting a discussion on the potential value chain of recycled materials, the processing of the ground compound will involve both scientific work and engineering work. To name a few points, the relation between the shredding technology and the size and distribution of the ground compound needs to be evaluated and hopefully 
Fig. 9 Bolt bearing test results

Fig. 10 a Typical forcedisplacement curve of the curved beam strength tests. b

Micrography of a typical interlaminar tensile failure

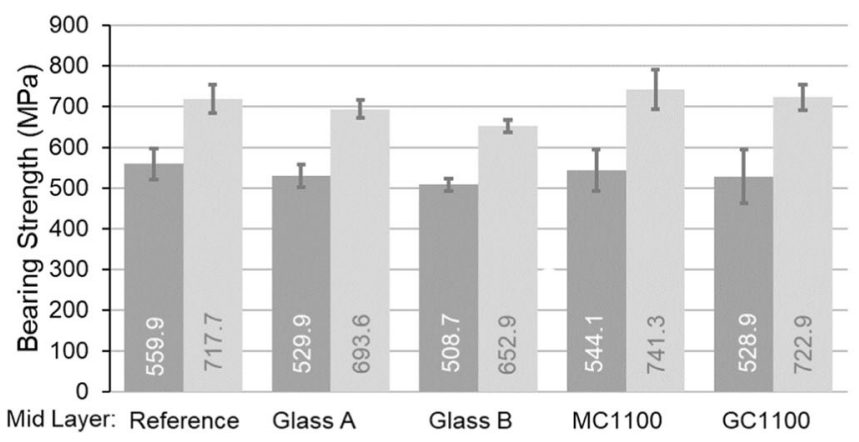

Initial Strength

Ultimate Strength

Error bars $= \pm S D$
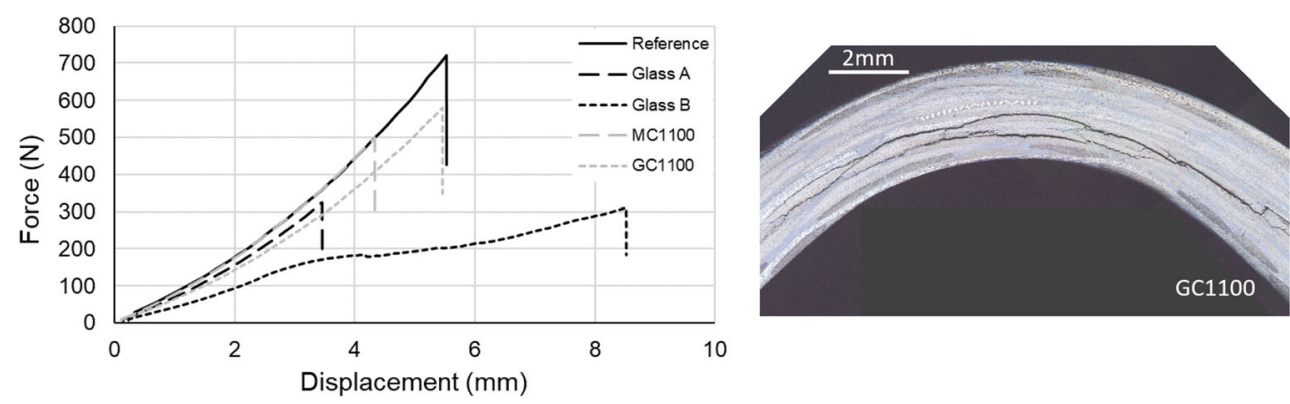

Table 7 Curved beam strength test results

Fig. 11 Curved beam strength test results

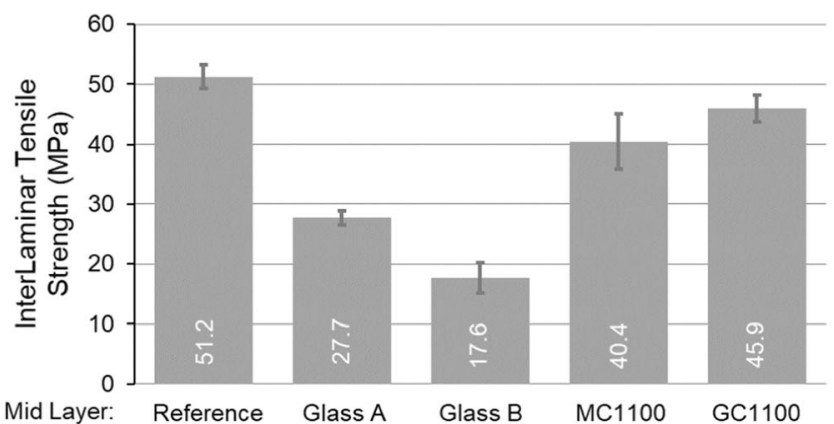

ILTS (MPa)

Glass A

Glass B

MC1100

GC1100

\begin{tabular}{llllll}
\hline Mid-plane material & Reference & Glass A & Glass B & MC1100 & GC1100 \\
\hline Sample size & 5 & 5 & 5 & 5 & 5 \\
$h_{\mathrm{a}}(\mathrm{mm})$ & 2.45 & 2.32 & 2.27 & 2.41 & 2.46 \\
$h_{\mathrm{c}}(\mathrm{mm})$ & 2.27 & 2.22 & 2.1 & 2.2 & 2.12 \\
$\theta_{0}\left({ }^{\circ}\right)$ & 87.3 & 87.4 & 87.2 & 87.1 & 86.8 \\
$\operatorname{rsd}(\%)$ & 0.2 & 0.2 & 0.2 & 0.8 & 0.4 \\
$\sigma_{z, \max }\left(\times 10^{6} \mathrm{~N} / \mathrm{m}^{2}\right)$ & 51.2 & 26.9 & 17.6 & 40.4 & 45.9 \\
rsd $(\%)$ & 3.9 & 4.8 & 14.5 & 11.4 & 4.7 \\
Fracture & Interlaminar & Interlaminar & Interlaminar & Interlaminar & Interlaminar \\
\hline
\end{tabular}


controlled. Other parameters of importance will also be the degradation of the polymer and the presence of secondary materials. The effect of size and distribution on the processability of the layer and on its performance of the compound still has to be clarified, where particular attention on the repeatability should be given.

This study focused on performance of laminates or blanks meant for the stampforming of shell-like products. The influence of the presence of a moulding compound on the formability of the shell should be addressed. The stampforming of the curved beam specimens discussed in this paper illustrates the potential effect of using such materials. It is mentioned in paragraph 3.1 that the stampforming using a negative elastomeric mould led to a thinner laminate in the corner section than in the flat sections. This shows that the compound will flow to a certain extent depending on the local geometrical changes leading to local pressure gradients. The pressing of similar curved beam specimens with a positive elastomeric mould shows the opposite trend, i.e. a thicker composite in the corner section than in the flat section.

\section{Conclusion}

This paper explored the possibility to use shredded thermoplastic laminates as one of the plies within a laminate. Although such moulding compounds are known to have lower performances than their continuous fibre-reinforced counterparts, positioning such plies within the laminate on a strategic position leads to a laminate having similar chosen properties. In this project, the lay-up was chosen making sure the continuous fibre reinforcement layers are loaded the most while the moulding compound layers are still able to transfer load through the thickness.

The results of the bending, bearing and curved beam strength tests show minimum performance knock-down factors. The choices made in terms of materials and lay-up are illustrative and were by no means meant to be optimised or serve as a basis for design rules. One could argue the moulding compound proposed acts as a filler within the laminate, though still guaranteeing a laminate having a normal consolidation quality.

The development of the points mentioned in the discussion and concerning the processing and performance characterisation should finally lead to a set of design rules answering the question on where to add such plies and how much, as a function of the application and the loading cases.
Acknowledgements The support of Martin Polane for the preparation of the laminates is kindly acknowledged.

\section{Compliance with ethical standards}

Conflict of interest The authors declare that they have no conflict of interest.

Open Access This article is licensed under a Creative Commons Attribution 4.0 International License, which permits use, sharing, adaptation, distribution and reproduction in any medium or format, as long as you give appropriate credit to the original author(s) and the source, provide a link to the Creative Commons licence, and indicate if changes were made. The images or other third party material in this article are included in the article's Creative Commons licence, unless indicated otherwise in a credit line to the material. If material is not included in the article's Creative Commons licence and your intended use is not permitted by statutory regulation or exceeds the permitted use, you will need to obtain permission directly from the copyright holder. To view a copy of this licence, visit http://creativecommons.org/licenses/by/4.0/.

\section{References}

1. Offringa AR (1996) Thermoplastic composites - rapid processing applications. Compos Part A 27:329-336

2. Abdul Rasheed MI (2016) Compression molding of chopped woven thermoplastic composite flakes. PhD Thesis, University of Twente

3. Vincent GA, de Bruijn TA, Abdul Rasheed MI, Wijskamp S, Akkerman R (2017) Fibre length distribution of shredded thermoplastic composite scrap. Proceedings of the $21^{\text {st }}$ International Conference on Composite Materials (ICCM/21) Xi' an

4. Luinge H, Warnet LL. (2016) Tuning performance of organosheets by hybridisation. Proceedings of the SAMPE Europe Conference 16, Liège

5. Swolfs Y, Gorbatikh L, Verpoest I (2014) Fibre hybridisation in polymer composites: a review. Compos Part A 67:181-200

6. Sacchetti F, Grouve WJB, Warnet LL, Fernandez Villegas I (2018) Effect of colling rate on the interlaminar fracture toughness of unidirectional carbon-PPS laminates. Eng Fract Mech 203:126-136

7. BS EN 2562:1997. Carbon fibre reinforced plastics. Unidirectional laminates. Flexural test parallel to the fibre direction

8. AITM 1-0009:2003 issue 3. Airbus test method: fibre reinforced plastics: determination of bearing strength by either pin or bolt bearing configuration

9. AITM 1-0069:2011 issue 2. Airbus test method: fibre reinforced plastics: determination of curved failure load

10. ASTM D6415: 2013. Standard test method for measuring the curved beam strength of a fiber-reinforced polymer-matrix composite

11. Kedward KT, Wilson RS, McLean SK (1989) The flexure of simply curved composite shapes. Composites 20:527-553

Publisher's note Springer Nature remains neutral with regard to jurisdictional claims in published maps and institutional affiliations. 